\title{
ANOPHELES (DIPTERA: CULICIDAE) SPECIES COMPLEX IN THAILAND: IDENTIFICATION, DISTRIBUTION, BIONOMICS AND MALARIA-VECTOR IMPORTANCE
}

\section{ATIPORN SAEUNG}

Department of Parasitology, Faculty of Medicine, Chiang Mai University, Chiang Mai 50200, Thailand.

*Corresponding Author: Email- atiporn44@yahoo.com

Received: May 11, 2012; Accepted: May 24, 2012

\begin{abstract}
Anopheles mosquitoes are still considered to be important vectors worldwide, with approximately 80 species of them incriminated as vectors of malaria, filarial nematode and encephalitis virus. Among these, at least 30 species exhibit species complexes, which comprise about 145 sibling species members. The exhibition of species complexes within the taxon of some Anopheles lead to complication of vector control that results from the difficulty in precisely identifying sibling (isomorphic) species members and their difference in biological characteristics. During the past 3 decades in Thailand, at least 6 malaria vectors, i.e., An. dirus, An. minimus, An. maculatus, An. sundaicus, An. barbirostris and An. leucosphyrus were proven to be species complexes. Thus, the objective of this review is to provide the current taxonomical information of Thai Anopheles species complexes, including techniques used in the identification of sibling species members, their geographic distribution, bionomic status and malaria-vector importance.
\end{abstract}

Key words- Anopheles, species complex, identification, distribution, trophic behavior, malaria vector, Thailand.

Citation: Atiporn Saeung (2012) Anopheles (Diptera: Culicidae) Species Complex in Thailand: Identification, Distribution, Bionomics and Malaria-Vector Importance. International Journal of Parasitology Research, ISSN: 0975-3702 \& E-ISSN: 0975-9182, Volume 4, Issue 1, pp.75-82.

Copyright: Copyright@2012 Atiporn Saeung. This is an open-access article distributed under the terms of the Creative Commons Attribution License, which permits unrestricted use, distribution, and reproduction in any medium, provided the original author and source are credited.

\section{Introduction}

Five malaria species (Plasmodium vivax, $P$. falciparum, $P$. malariae, $P$. ovale and $P$. knowlesi) transmitted by Anopheles mosquitoes are still a major public health problem in the world. At least 109 countries, comprising 8 parts (Africa, Asia, the Middle East, Eastern Europe, Central and South America, Hispaniola and Oceania) of tropical and subtropical regions are endemic areas of these parasites, and threaten the health of about 250 million people per year [1]. Recently, $P$. knowlesi, a primate malaria parasite in macaques, was first reported to infect humans in the Malaysian peninsular [2]. In Thailand, the most common malaria species are $P$. vivax and $P$. falciparum, whereas $P$. malariae and $P$. ovale are rare [3-4]. However, a total of 35 cases of $P$. knowlesi were reported recently from 6 provinces, comprising 3 regions in Thailand, i.e., western (Tak and Prachuap Khiri Khan provinces), eastern (Chanthaburi province) and southern (Ranong, Yala and Narathiwat provinces) [5-8]. Regarding $P$. ovale, based on DNA samples from Ghana, Myanmar, Nigeria, Sao Tome, Sierra Leone and Uganda, at least two distinct new species, i.e., $P$. ovale curtisi (classic type) and $P$. ovale wallikeri (variant type), have been described recently [9]. Nonetheless, the real identity of these two new malaria species in Thailand is still a crucial question, which requires further intensive investigation. The disease is limited generally to rural communities living in and near forested areas, mountains and foothills, particularly those residing in newly opened land settlements of semi forested areas and earning their living by growing agricultural crops as well as those living in areas near and along the borders with neighboring Cambodia, Laos, Myanmar and Malaysia [3-4].

At least 21 Anopheles species are reported in Thailand as primary (regional), secondary (local) and suspected vectors of malaria. The primary vectors are An. dirus, An. baimaii, An. minimus and An. maculatus, while An. aconitus, An. pseudowillmori and An. epiroticus are considered as secondary vectors, based on the recovery of sporozoites from salivary glands and their geographic distribution [10-18]. The remaining 14 species, i.e., An. annularis, An. barbirostris, An. campestris, An. hodgkini, An. karwari, An. kochi, An. nigerrimus, An. nivipes, An. peditaeniatus, An. philip- 
pinensis, An. sawadwongporni, An. sinensis, An. tessellatus and An. vagus are suspected vectors, based on positive oocysts in the midgut and/or enzyme linked immunosorbent assay of circumsporozoite antigens [11, 13, 15, 19-26]. An. barbirostris/campestris group are considered as potential vectors that play an important role in the increasing cases of $P$. vivax infection in Thailand, based on their anthropophillic behavior, and high oocyst and sporozoite rates from laboratory susceptibility tests $[27-29,111]$. An. latens and $A n$. cracens, have been incriminated recently as natural vectors of $P$. knowlesi in the Malaysian peninsular [30-31], and are thus, considered provisionally as possible vectors that might play a role in transmitting this malaria parasite in the southern region, based on their distribution in southern Thailand.

Although vector control programs have been established in Thailand for a long time, the diseases continue to be endemic year by year. The partial failure to control vectors has many components, e.g., no and/or incomplete insecticide spraying in the household, change in vector biting habits, vector tolerance or resistance to insecticides and its exhibition of species complexes [32-34]. The last factor appears to be important and presumably affects all other aspects, since it leads to difficulty in precisely identifying sibling species members that possess identical morphology or minimal morphological distinction. In addition, those members may differ in biological characteristics (e.g., microhabitats, resting and biting behavior, sensitivity or resistance to insecticides, susceptible or refractory to malaria parasites, etc.), which can be used to determine their potential for transmitting diseases. Incorrect identification of individual members in Anopheles species complexes may result in failure to distinguish between a vector and nonvector, and lead to complications and/or unsuccessful vector control [34-35].

Throughout the world, a total of 478 species of Anopheles mosquitoes have been discovered, and approximately 80 of them play an important role as vectors of malaria, filarial nematode and encephalitis virus. Among these, at least 30 species exhibit species complexes, which comprise about 145 sibling species members [3437]. In Thailand, significant progress has been made in the population genetic study of primary vectors: An. dirus [38-43], An. minimus [44-51] and An. maculatus [52-58]; secondary vectors: An. aconitus [59], An. maculatus (species I/pseudowillmori) [60] and An. sundaicus [16, 61-63]; suspected vectors: An. maculatus (species A/sawadwongporni) [64], An. sinensis [65], An. peditaeniatus [66] and An. vagus [67]; potential vectors: An. barbirostris/campestris group [68-71]; and possible vector: An. leucosphyrus [72]. However, only 6 species, i.e., An. dirus, An. minimus, An. maculatus, An. sundaicus, An. barbirostris and An. leucosphyrus, exhibited species complexes.

\section{Techniques used in the identification of sibling species mem- bers}

So far, at least 1 or 2 traditional techniques have been used widely for the recognition of sibling species within the taxon Anopheles species complex at post- and pre-mating barriers. For post-mating barriers; the hybridization or crossing experiment, using the artificial mating technique to determine hybrid non-viability, sterility or breakdown, is still a useful tool for identifying sibling species members of each complex. Detailed genetic incompatibility, including lack of insemination, embryonation, hatchability, larval survival, pupation, emergence, adult sex distortion, abnormal reproductive system and complete or incomplete (only at the inversion heterozygote regions in some cases) asynaptic salivary gland polytene chromosomes are useful criteria for elucidating species complex status. However, a point worth noting is that an iso-female line (isoline) colony established from the combinative characters of morphological and/or cytological markers has to be considered seriously. A laboratory raised colony established from a naturally mixed population should be omitted, since it may be a mixture of cryptic species [34, 38-39, 41, 73]. As for pre-mating barriers; examination of the polytene chromosomes in wild-caught adult females, and/or progenies of isolines, provides clear evidence that different specific mate recognition systems (SMRS) exist. The total absence or significantly deficient number of heterozygotes for an inversion in a population entirely indicates the presence of reproductive isolation within a taxon $[34,54,59,74]$. Nonetheless, at least 3 problems have been raised regarding this matter, i.e., (1) a skilled person is needed to prepare a perfect chromosome and make an identification, (2) homosequential banding species cannot be employed, e.g., An. maculipennis complex [75] and An. barbirostris complex [68-71], and (3) a relatively large amount of sample materials are required to perform the Hardy-Weinberg equilibrium, which cannot be applied to small numbers of rare species specimens that are caught during specific seasons. Electrophoretic variations at enzyme loci are not only useful for identification of sibling species, but also for the correct identification of morphologically cryptic Anopheles species. Variations at a locus thus enable detection of reproductive isolation within populations, resulting from positive assortative (preferential) mating [34, 47, 74]. Nevertheless, at least 2 problems have been raised regarding this technique, i.e., (1) specimens must be fresh or frozen until analysis, and (2) its use must be similar to that of the polytene chromosome, as it requires a relatively large amount of sample materials to perform the Hardy-Weinberg equilibrium, as previously described.

In light of the advantages and disadvantages of the techniques mentioned above, the rapid systematic procedures for the identification of Anopheles species complexes were formed recently [76]. This was done by crossing experiments among iso-female lines using karyotypic markers (characteristics of metaphase karyotypes/karyotypic forms) related to DNA markers [comparative DNA sequence analyses of some specific genomic loci (e.g., ribosomal DNA: ITS2; mitochondrial DNA: COI, COII) that determined large sequence divergence or very low intraspecific sequence variation] of each isoline colony. By applying of this rapid systematic procedure, 5 sibling species members i.e., An. barbirostris species A1, $\mathrm{A} 2, \mathrm{~A} 3$ and $\mathrm{A} 4$, and $A n$. campestris-like, have been identified in the taxon An. barbirsotris within the last 2 years [68-71]. Remarkably, rare allopatric species with few isolines such as $A n$. barbirostris species $A 3$ and $A 4$, which could be caught in a specific season and/or locality, continue to perform genetic proximities among other sibling species members. In addition, the 5 sibling species members of An. barbirsotris complex exhibited homosequential banding patterns of salivary gland polytene chromosomes, with a marked limitation of use to investigate their pre-mating barriers by determining inverted heterozygote in a natural sympatric population. 


\section{Geographic distribution, bionomics and malaria-vector im-} portance

Regarding the difference in geographic distribution, trophic behavior, vector competence and malaria-vector importance among sibling species members within the taxon Anopheles vectors, great progress or positive findings have been recovered in the studies of An. dirus complex, An. minimus complex, An. maculatus complex, An. sundiacus complex, An. baribrostris complex and An. leucosphyrus complex. Summarization of geographic distribution is shown in Fig. 1, known sibling species members related to malaria-vector importance are demonstrated in Table 1, and details are as follows:

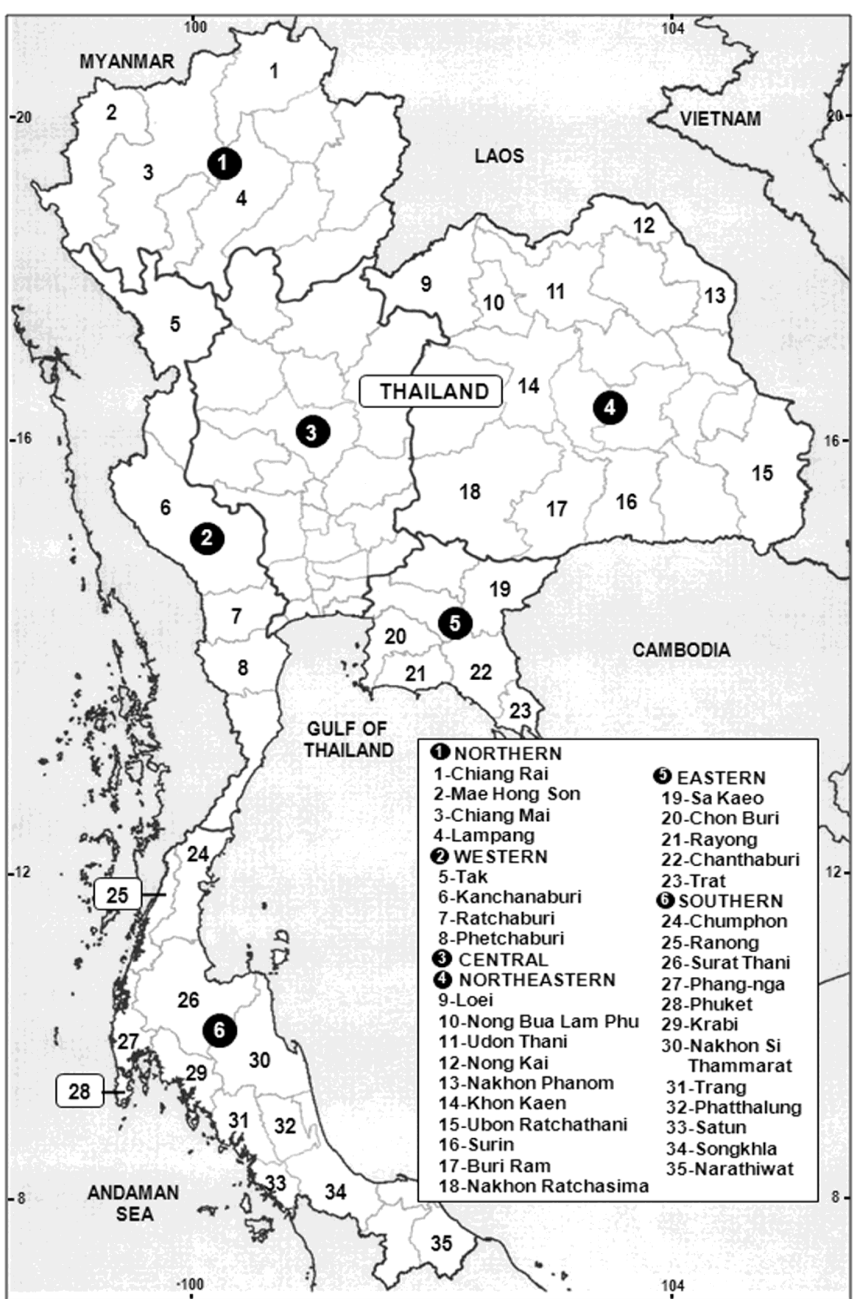

Fig. 1- Map of Thailand, showing distribution of the species members of 6 Anopheles species complexes. Cosmopolitan distribution across 6 regions: An. barbirostris species A1, An. campestris-like, An. dirus, An. maculatus and An. minimus. Distribution in some specific provinces: An. baimaii (5, 6, 25, 27, 29); An. barbirostris species A2 (4, 7, 8, 11, 15, 22), A3 (6) and A4 (3); An. cracens (27, 29, 31, 32, 34); An. dravidicus (1, 2, 3, 5, 6, 9, 18); An. epiroticus $(21,22,23,24,27,28,29,30,31,33,34)$; An. harrisoni $(3,5$, $6)$; An. latens $(30,35)$; An. maculatus Form E (24, 34); An. nemophilous (5, 6, 25, 27, 30, 34); An. notanandai (7, 8); An. pseudowillmori (1, 2, 3, 5, 9, 12); An. rampae (10, 12, 13, 15); An. sawadwongporni $(18,25,27)$; An. scanloni $(6,25,27,29,30,31$, $32)$; and An. willmori (3).
Table 1-Known sibling species members of Anopheles species complexes as primary, secondary, suspected, potential and possi-

ble malaria-vectors in Thailand and neighboring countries

\begin{tabular}{|c|c|c|c|c|}
\hline \multirow{4}{*}{$\begin{array}{l}\text { Species complexes/ } \\
\text { sibling species members }\end{array}$} & \multicolumn{2}{|c|}{ Human malaria } & \multicolumn{2}{|c|}{ Macaque malaria } \\
\hline & \multicolumn{2}{|c|}{$\begin{array}{l}\text { (P. vivax, } P \text {. falciparum, } P \text {. } \\
\text { malariae and } P \text {. ovale) }\end{array}$} & \multicolumn{2}{|c|}{ (P. knowlesi) } \\
\hline & Vector in & Vector in & Vector in & \\
\hline & Thailand & $\begin{array}{l}\text { neighboring } \\
\text { countries }\end{array}$ & Thailand & $\begin{array}{l}\text { neighboring } \\
\text { countries }\end{array}$ \\
\hline \multicolumn{5}{|l|}{ An. dirus complex } \\
\hline An. dirus & 1 & + & - & - \\
\hline An. baimaii & 1 & - & - & - \\
\hline An. cracens & - & - & 5 & + \\
\hline An. minimus complex & & & & \\
\hline $\begin{array}{l}\text { An. minimus } \\
\text { An. maculatus complex }\end{array}$ & 1 & + & - & - \\
\hline An. maculatus & 1 & + & - & - \\
\hline An. pseudowillmori & 2 & - & - & - \\
\hline $\begin{array}{l}\text { An. sawadwongporni } \\
\text { An. sundaicus complex }\end{array}$ & 3 & - & - & - \\
\hline $\begin{array}{l}\text { An. epiroticus } \\
\text { An. barbirostris complex }\end{array}$ & 2 & + & - & - \\
\hline $\begin{array}{l}\text { An. campestris-like } \\
\text { An. leucosphyrus complex }\end{array}$ & 4 & - & - & - \\
\hline An. latens & - & + & 5 & + \\
\hline
\end{tabular}

1- primary vector, 2- secondary vector, 3- suspected vector, 4- potential vector, 5- possible vector

An. dirus complex- Morphological variations observed in natural populations, biological and behavioral difference of laboratory bred colonies (stenogamy or eurygamy), cytological [metaphase karyotypes and salivary gland polytene chromosomes: differences in banding patterns at the free ends of $1(X), 2(2 R)$ and $3(2 \mathrm{~L})]$ analyses of laboratory colonized and natural populations, and crossing experiments among isoline colonies have led to the recognition of 7 sibling species members of this complex, i.e., An. dirus (dirus A), An. cracens (dirus B/balabacensis Perlis Form), An. scanloni (dirus C), An. baimaii (dirus D), An. elegans (dirus E), An. nemophilous (dirus F) and An. takasagoensis [39, 41, 73, 7782] In Thailand, only five sibling species members, i.e., An. dirus, An. cracens, An. scanloni, An. baimaii and An. nemophilous are found indigenously [83]. An. dirus is a cosmopolitan species that distributes across 6 regions (northern, southern, central, northeastern, eastern and southern) in Thailand, while An. baimaii, An. cracens, An. nemophilous and An. scanloni distribute in sympatric with $A n$. dirus in western and/or southern regions. Detailed species distributions together with regions and/or provinces are illustrated in Fig. 1.

Observation on the biting activity of An. baimaii, An. cracens, An. dirus and An. scanloni revealed that these four isomorphic species feed at different times during the night [84]. The case of early biting in An. scanloni at Nakhon Si Thammarat province, southern Thailand, is strikingly different from cases in the other species, although all of them are anthropophilic. Outdoor biting activity of An. scanloni is normally at a high level in early evening, at around 18:00-20:00 h. It then declines sharply and is maintained at a very low level throughout the second half of the night. An. cracens at Phatthalung province, southern Thailand, exhibited a slightly different feeding activity from An. scanloni, with a peak period of outdoor biting time at around 19:00-21:00 h, and a low level main- 
tained throughout the second half of the night. Interestingly, in 20 years, this biting peak has been mostly in agreement with the biting activity of An. cracens (peak period: 19:00-20:00 h) strain from the State of Pahang, Malaysia, which is adjacent to southern Thailand [31]. In contrast, the outdoor biting activity of An. dirus at Phitsanulok province, central Thailand, started somewhat later in the first half of the night, with a peak period at around 21:00-23:00 $\mathrm{h}$. The outdoor biting activity of An. baimaii at Krabi province, southern Thailand, was even later than the others, beginning at a low level and gradually increasing to a peak period in the second half of the night at around 01:00-03:00 h. Among these, An. dirus and $A n$. baimaii were incriminated as primary vectors of $P$. vivax and $P$. falciparum [13-14, 83], while An. cracens was a possible natural vector of $P$. knowlesi in southern Thailand, based on its distribution there, and also incriminated as a natural vector of $P$. knowlesi in Kuala Lipis District in the State of Pahang, Malaysia [31] (Table 1).

An. minimus complex- Three sibling species members were recovered within the taxon An. minimus complex, i.e., An. minimus (minimus A), An. harrisoni (minimus $\mathrm{C}$ ) and $A n$. yaeyamaensis (minimus $\mathrm{E}$ ). Morphological ( $\mathrm{M}, \mathrm{V}$ and $\mathrm{P}$ forms) and isoenzyme (esterase and octanol dehydrogenase) studies together have recognized An. minimus and An. harrisoni in a sympatric population [44, 47], while An. yaeyamaensis was discovered by crossing experiments relating to comparative morphological, cytological (metaphase karyotypes) and DNA (D3 region) investigations with An. minimus and An. harrisoni [85-87]. An. minimus is the predominant species of the complex and distributes across 6 regions in Thailand, and also in the Oriental region (India, Vietnam, China and Taiwan) [34, 47, 88-91] An. harrisoni was recorded commonly in Kanchanaburi province, central Thailand, and found in sympatric with An. minimus, but absent or rare in other provinces [44, 47, 49] (Fig. 1). Based on enzyme electrophoresis, An. harrisoni has been reported in Vietnam [90], where it occurs in sympatric with An. minimus in varying proportions depending upon locality, host preferences and season. An. yaeyamaensis has so far been reported from only islands of the Ryukyu Archipelago, Japan [85, 87].

Observation on the biting activities of An. minimus and An. harrisoni at Ban Phu Toei, Sai Yok district, Kanchanaburi province, western Thailand revealed that An. minimus bit on humans more than animals, while An. harrisoni bit mainly on animals [44]. These results were contrary to subsequent studies, although the same area of interest was investigated [92]. The results revealed that both An. minimus and An. harrisoni tended to feed from cows rather than humans, and they did not find any preference for indoor-, outdoor- or forest-biting in either species. Both species had a peak biting density in October/November, at the end of the rainy season. Additional studies by other investigators in western Thailand indicated that An. minimus is mainly anthropophilic, endophagic and exophilic, while An. harrisoni has shown a greater tendency of zoophily, exophagy and exophily. An. harrisoni exibits two peaks of biting activity, the first in the early evening, between 18:00-21:00 h, with a second small peak from midnight to $02: 00 \mathrm{~h}$ or from 03:00-06:00 h, whereas An. minimus tends to bite later, with peak activity occurring around 22:00 h [22, 93-94]. An. minimus was incriminated as a primary vector of malaria in Thailand
[12, 14-15], whereas the vector status of An. harrisoni for transmitting malaria in nature has not been determined up to this time (Table 1). However, reports on laboratory susceptibility to $P$. vivax and $P$. falciparum of these 2 anopheline species indicated that $A n$. minimus and An. dirus yielded rather similar susceptibility rates to both in $P$. vivax [oocyst rates (8 days post-infection): minimus $=$ 81.82, dirus $=100$; sporozoite rates (12 days post-infection): minimus $=77.78$, dirus $=100]$ and $P$. falciparum [oocyst rates $(8$ days post-infection): minimus $=91.67$, dirus $=100 ;$ sporozoite rates $(12$ days post-infection): minimus $=100$, dirus $=95.65$ ], whereas $A n$. minimus yielded higher susceptibility rates to $P$. vivax than $A n$. harrisoni [0ocyst rates ( 8 days post-infection): minimus $=81.82$, An. harrisoni $=50.00$; sporozoite rates ( 12 days post-infection): minimus $=77.78$, An . harrisoni $=52.17]$, although they had no statistically significant difference [59]

An. maculatus complex- Comparative morphological (reduced abdominal scaling, heavy abdominal scaling and non-scaly forms) and cytological [metaphase chromosomes and ovarian nurse cell polytene chromosomes: $1(\mathrm{X})$ and $2(2 \mathrm{R})$ ] studies together have identified 8 sibling species members in this complex [An. sawadwongporni (species A), An. maculatus (species B plus metaphase karyotype Form E), An. dravidicus (species C), An. notanandai (species G), An. willmori (species H), An. pseudowillmori (species I), An. greeni (species D) and An. dispar (species J)] [55-56, 83, 95-99]. Recently, An. rampae (maculatus metaphase karyotype Form K) was identified by crossing experiments relating to comparative morphological, cytological (metaphase and polytene chromosomes) and molecular (rDNA: ITS2, D3; mtDNA: COII, ND5) investigations with other species members [100-104]. In Thailand, seven species members, i.e., An. sawadwongporni, An. maculatus (plus Form E), An. dravidicus, An. notanandai, An. willmori, An. pseudowillmori and An. rampae are found, while An. greeni and An. dispar are indigenous to the Philippines [34, 83, 104-105]. Regarding distribution of the species members of $A n$. maculatus complex in Thailand, An. maculatus is a cosmopolitan species that distributes across 6 regions in Thailand, but An. maculatus Form $\mathrm{E}$ is limited to only the southern region. An. dravidicus and An. pseudowillmori are found sympatric with An. maculatus in northern, western and northeastern regions. An. sawadwongporni is recorded in northeastern and southern regions, whereas $A n$. willmori and An. notanandai are confined only to northern and western regions, respectively (Fig. 1).

Biting activities of the species members of An. maculatus complex in Thailand were studied in Pakchong district, Nakhon Ratchasima province, central Thailand and Sadao district, Songkhla province, southern Thailand [106]. In Pakchong district, An. sawadwongporni was the most dominant species, followed by An. maculatus and An. dravidicus, which were rare. The densities of An. sawadwongporni and An. maculatus were high between July and November, with their peaks in October. Biting activities of both species occurred throughout the night, with a major peak during the first quarter of the night in all seasons. Similar result of peak duration between 18:00-20:00 $\mathrm{h}$ was obtained from the bites of $A n$. maculatus in Tak province, western Thailand [22]. In Sadao district, only An. maculatus (plus Form E) was obtained with peak densities between February and June. Biting activities of this species varied according to the season. All species identified in the 
study were found to be predominantly zoophagic and preferred to bite humans outdoors, rather than indoors. Apart from these, An. maculatus and An. pseudowillmori have been incriminated as primary and secondary vectors of malaria in southern and western region, respectively, while An. sawadwongporni is considered as a suspected malaria-vector [14, 55, 83] (Table 1).

An. sundaicus complex- At least 5 sibling species members, i.e., An. epiroticus (sundaicus A), An. sundaicus s.s. (sundaicus B and $C)$, An. sundaicus $D$ and $A n$. sundaicus $E$ were discovered within this complex, and only An. epiroticus was found indigenously in Thailand $[11,83]$. An. sundaicus $A, B$ and $C$ were recognized based on the distinct characteristics of metaphase karyotypes (Form A, B and C) together with ovarian nurse cell polytene chromosomes [distinct banding patterns at the tip of chromosome 1 $(\mathrm{X})$ and at the proximal region of chromosome arm 2 (2R)] [62]. Additional evidence to ascertain their biological species resulted from positive assortative mating for 12 enzyme-electromorph loci and phylogenetic dendrogram mixtures of An. sundaicus A, B and $C$ were created [63]. The evidence to support An. sundaicus $D$ is the discovery of a new cytogenetic variant (cytotype D), which was raised from the combinative characteristics of the ovarian nurse cell polytene chromosome of An. sundaicus A and C (Xa and $2 \mathrm{Rb}$ chromosomal-typed) [107]. Molecular identification using ITS2 and D3 regions, which could separate An. sundaicus D from An. sundaicus $A, B$ and $C$, formed strong supportive evidence [108]. Based on the $2.1 \%$ mean sequence variation in both $\mathrm{COI}$ and cytochrome b (Cyt-b) genes of mtDNA among An. sundaicus $A, B$ and $C$, the formerly named $A n$. sundaicus $A$ was proposed as An. epiroticus [16]. Additionally, phylogeography investigation of An. sundaicus s.l. collected from Indonesia, based on COI and Cyt-b sequences, revealed a distinct species, which was designated as An. sundaicus E [109]. Subsequently, an allele specific PCR was developed for distinguishing among An. epiroticus, An. sundaicus $\mathrm{B}$ and $\mathrm{C}$, and $A n$. sundaicus $\mathrm{E}$ [110].

An. sundaicus s.l. is considered as a vector of malaria in coastal areas of some countries, and is distributed widely in Oriental regions, extending from India, east to China through Bangladesh, Myanmar, Indochina, Thailand, Malaysia, Singapore and Indonesia [11, 83, 111-112]. It is generally a brackish water breeder, but An. epiroticus from south Tapanuli, north Sumatra, Indonesia [6263], and An. sundaicus D from Teressa, Nancowry, Car Nicobar and Katchal islands, India [108], are freshwater breeders. An. sundaicus $E$ is found to be restricted in Sumatra and Java, Indonesia [109]. In Thailand, only An. epiroticus has been recorded and is widespread along the coastal areas of eastern and southern regions [11, 62-63, 83]. (Fig. 1).

Adult females of An. sundaicus s.l. rest by day both indoors and outdoors, and are attracted more to cattle than humans but readily bite the latters indoors $[11,111]$. Recently, the bionomic status of An. epiroticus has been performed intensively in Rayong province, eastern Thailand. The biting pattern increased during 18:00-20:00 $\mathrm{h}$ and maximized at midnight (21:00-24:00 h). A total of 926 wildcaught female An. epiroticus was investigated for $P$. falciparum and $P$. vivax by using Nested PCR and real-time PCR techniques. The results revealed that 3 and 6 specimens were positive for $P$. falciparum and $P$. vivax, respectively. In addition, the overall annual entomological inoculation rate (EIR) and parity rate of this spe- cies was 76.6 and 74, respectively [113]. These results confirmed the secondary vector status of An. epiroticus in coastal locations of Thailand, as in former reports [11] (Table 1).

An. barbirostris complex- Five sibling species members, i.e., An. barbirostris species A1, A2, A3 and A4 and An. campestrislike, were recognized recently within the taxon An. barbirostris complex by means of crossing experiments among isolines relating to morphological characters (summation of seta 2-VI of pupal skins), cytogenetic forms (metaphase karyotypes) and DNA sequence analysis of ribosomal DNA (ITS2) and mitochondrial DNA (COI, COII) [68-71].

Observation on biting behavior of wild females indicated that $A n$. barbirostris species A1, A2, A3 and A4 are zoophily, exophagy and exophily, whereas An. campestris-like is anthropophilic, exophagic and exophilic [68-71]. Studies on distributional characteristics of the species members of An. barbirostris complex revealed that $A n$. barbirostris species A1, A2, A3 and A4 are forestedmountainous anophelines, while An. campestris-like is a plainlocation species. An. barbirostris species A1 is distributed widely across 6 regions in Thailand, whereas An. barbirostris species A2 occurs sympatrically with $A n$. barbirostris species A1 in some populations of northern, western, northeastern and eastern regions. An. barbirostris species A3 and A4 were confined to western and northern regions, respectively. An. campestris-like was a cosmopolitan species in plain localities throughout Thailand (Fig. 1).

The potential vector status of 5 species members of $A n$. barbirostris complex for malaria parasites was investigated by artificial membrane feeding on blood containing gametocytes of $P$. falciparum and $P$. vivax, and dissected for oocyst and sporozoite rates 8 and 14 days post blood-meal [71]. The total non-development of oocysts and sporozoites from An. campestris-like (Chiang Mai and Udon Thani strains), and An. barbirostris species A3 and A4 indicated that these anophelines were entirely refractory vectors for $P$. falciparum. The low normal development of oocysts (oocyst rates: 40-60) and sporozoites (sporozoite rates 6.67-11.76) recovered from An. barbirostris species A1, A2 and A3, demonstrated their low potential vectors for $P$. vivax. The high normal development of oocysts (oocyst rates: 100) and sporozoites (sporozoite rates: 64.29-66.67) obtained from An. campestris-like (Chiang Mai strain) indicated their high potential vectors for $P$. vivax. The present results confirmed the potential vector status of the An. barbirostris/campestris group in transmitting $P$. vivax in Thailand [2729] (Table 1). Additionally, this information asserted the previous proposed that different sibling species members within the complexes may result in the difference in malarial vector-competence, and lead to the complication of vector control-approaches [34].

An. leucosphyrus complex- So far, 2 sibling species member, i.e., An. latens (leucosphyrus A) and An. leucosphyrus (leucosphyrus B) have been discovered within this taxon. An. latens was distributed in southern Thailand (Fig. 1), the Malaysian peninsular and Kalimantan, while An. leucosphyrus was found mainly in Sumatra, Indonesia [72, 111]. Observation on the biting activity of An. latens in Kapit district, Sarawak, Malaysian Borneo indicated that it started biting from 18:00 h, with a peak biting time between 19:00 and 20:00 $\mathrm{h}$ in the forest, as opposed to between 
01:00 and 02:00 $\mathrm{h}$ on the farm [114]. An. latens (formerly as An. leucosphyrus s.l.) has been incriminated as a vector of human malaria in Sarawak and Sumatra [111], and it was reported recently as a natural transmitted-vector of $P$. knowlesi from macaques to humans in Kapit District, Sarawak, Malaysian Borneo [30]. It was also thought to be a possible vector in transmitting $P$. knowlesi to humans in southern region [5-8] (Table 1).

\section{Conclusion}

The difference in geographic distribution, trophic behavior, vector competence and malaria-vector importance among sibling species members within the taxon An. dirus complex, An. minimus complex, An. maculatus complex, An. sundaicus complex, An. barbirostris complex and An. leucosphyrus complex in Thailand, as in the detailed information above, indicates the significance of control approaches. All outstanding information is necessary for intensive evaluation and proper selection in forming a low cost and highly effective control strategy in order to interrupt the transmission of malaria parasites by these Anopheles vectors at specific locations and/or comparatively wide-range geography.

\section{Acknowledgements}

I am grateful to Professor Wej Choochote, Department of Parasitology, Faculty of Medicine, Chiang Mai University, Chiang Mai, Thailand, for his encouragement and valuable suggestions regarding this review article, and the Thailand Research Fund through the Royal Golden Jubilee Ph.D. Program (Grant No. PHD/0052/2548), Biodiversity Research and Training Program (Grant No. BRT R_249004, BRT R_250009 and BRT R_252005: 2006-2009) and Faculty of Medicine Research Fund, Chiang Mai University, Chiang Mai, Thailand, for financially supporting the study of An. barbirostris complex in Thailand

\section{References}

[1] WHO. (2008) In WHO/HTM/GMP/2008.2.1 (Geneva, http:// www.who.int/malaria/wmr2008/malaria2008.pdf), 215 p.

[2] Chin W., Contacos P.G., Coatney G.R. and Kimball H.R. (1965) Science., 149, 865.

[3] Annual report (1998) Thailand, Division of Malaria, Department of Communicable Disease Control, Ministry of Public Health.

[4] Annual report (2002) Thailand, Division of Malaria, Department of Communicable Disease Control, Ministry of Public Health.

[5] Jongwutiwes S., Putaporntip C., Iwasaki T., Sata T. and Kanbara H. (2004) Emerg. Infect. Dis.,10, 2211-2213.

[6] Putaporntip C., Hongsrimuang T., Seethamchai S., Kobasa T., Limkittikul K., Cui L. and Jongwutiwes S. (2009) J. Infect. Dis., 199, 1143-1150.

[7] Jongwutiwes S., Buppan P., Kosuvin R., Seethamchai S., Pattanawong U., Sirichaisinthop J. and Putaporntip C. (2011) Emerg. Infect. Dis., 17, 1799-1806.

[8] Sermwittayawong N., Singh B., Nishibuchi M., Sawangjaroen N. and Vuddhakul V. (2012) Malar. J., 11, 36.

[9] Sutherland C.J., Tanomsing N., Nolder D., Oguike M., Jennison C., Pukrittayakamee S., Dolecek C., Hien T.T., do Rosário V.E., Arez A.P., Pinto J., Michon P., Escalante A.A., Nosten F., Burke M., Lee R., Blaze M., Otto T.D., Barnwell
J.W., Pain A., Williams J., White N.J., Day N.P., Snounou G., Lockhart P.J., Chiodini P.L., Imwong M. and Pol-ley S.D. (2010) J. Infect. Dis., 201, 1544-1550.

[10]Gould D.J., Esah S. and Pranith U. (1967) Trans. R. Soc. Trop. Med. Hyg., 61, 441-442.

[11]Scanlon J.E., Peyton E.L. and Gould D.J. (1968) Thai. Natl. Sci. Pap. Fauna. Ser., 2, 1-35.

[12]Harrison B.A. (1980) Contrib. Am. Entomol. Inst., 17, 1-195.

[13]Rosenberg R., Andre R.G. and Somchit L. (1990) Trans. R. Soc. Trop. Med. Hyg., 84, 22-28.

[14]Green C.A., Rattanarithikul R., Pongprasit S., Sawadwongporn P. and Baimai V. (1991) Trans. R. Soc. Trop. Med. Hyg., 85, 35-36.

[15]Rattanarithikul R., Linthicum K.J. and Konishi E. (1996) J. Am. Mosq. Control. Assoc., 12, 75-83.

[16]Linton Y.M., Dusfour I., Howard T.M., Ruiz L.F., Duc Manh N., Ho Dinh T., Sochanta T., Coosemans M. and Harbach R.E. (2005) Bull. Entomol. Res., 95, 329-339.

[17]Sallum M.A.M., Peyton E.L., Harrison B.A. and Wilkerson R.C. (2005) Rev. Brasil. Entomol., 49 (Suppl 1), 1-152.

[18]Sallum M.A.M., Peyton E.L. and Wilkerson R.C. (2005) Med. Vet. Entomol., 19, 158-199.

[19]Harrison B.A. and Scanlon J.E. (1975) Contrib. Am. Entomol. Inst., 12, 78.

[20]Harinasuta T., Gilles H.M. and Sandosham A.A. (1976) Southeast Asian J. Trop. Med. Public. Health., 7, 645-678.

[21]Baker E.Z., Beier J.C., Meek S.R. and Wirtz R.A. (1987) J. Med. Entomol., 24, 536-541.

[22]Harbach R.E., Gingrich J.B. and Pang L.W. (1987) J. Am. Mosq. Control. Assoc., 3, 296-301.

[23]Gingrich J.B., Weatherhead A., Sattabongkot J., Pilakasiri C. and Wirtz R.A. (1990) J. Med. Entomol., 27, 1016-1026.

[24]Frances S.P., Klein T.A., Wirtz R.A., Eamsila C., Pilakasiri C. and Linthicum K.J. (1996) J. Med. Entomol., 33, 990-991.

[25]Somboon P., Aramrattana A., Lines J. and Webber R. (1998) Southeast Asian J. Trop. Med. Public. Health., 29, 3-9.

[26]Coleman R.E., Sithiprasasna R., Kankaew P., Kiaattiut C., Ratanawong S., Khuntirat B. and Sattabongkot J. (2002) J. Med. Entomol., 39, 556-559.

[27]Limrat D., Rojruthai B., Apiwathnasorn C., Samung Y. and Prommongkol S. (2001) Southeast Asian J. Trop. Med. Public. Health., 32, 739-744.

[28]Apiwathnasor C., Prommongkol S., Samung Y., Limrat D. and Rojruthai B. (2002) J. Med. Entomol., 39, 583-586.

[29]Sattabongkot J., Tsuboi T., Zollner G.E., Sirichaisinthop J. and Cui L. (2004) Trends. Parasitol., 20, 192-198.

[30]Vythilingam I., Tan C.H., Asmad M., Chan S.T., Lee K.S. and Singh B. (2006) Trans. R. Soc. Trop. Med. Hyg., 100, 10871088.

[31]Vythilingam I., Noor Azian Y.M., Tan C.H., Adela I.J., Yusri Y.M., Azahari A.H., NorParina I., Noor Rain A. and Hakim L.S. (2008) Parasit. Vectors., 1, 26.

[32] Ismail I.A., Phinichpongse S. and Boonrasri P. (1978) Acta. Trop., 35, 69-82.

[33]WHO. (1992) WHO. Tech. Rep. Ser., 818, 1-62.

[34]Subbarao S.K. (1998) WHO. Tech. Pub. Ser., 18, 1-82.

[35]WHO. (2007) SEARO. Tech. Pub., 57, 1-102.

[36][36]Manguin S., Bangs M.J., Pothikasikorn J. and 
Chareonviriyaphap T. (2010) Infect. Genet. Evol., 10, 159177.

[37]Harbach R.E. (2011) Mosquito Taxonomic Inventory, http:// mosquito-taxonomic-inventory.info/. accessed on 7 May 2012.

[38]Kanda T., Takai K., Chiang G.L., Cheong W.H. and Sucharit S. (1981) Jpn. J. Sanit. Zool., 32, 321-329.

[39]Baimai V., Harbach R.E. and Kijchalao U. (1988) J. Am. Mosq. Control. Assoc., 4, 333-338.

[40]Baimai V., Thu M.M., Paing M. and Maheswary N.P. (1988) Southeast Asian J. Trop. Med. Public. Health., 19, 661-665.

[41]Sawadipanich Y., Baimai V. and Harrison B.A. (1990) J. Am. Mosq. Control. Assoc., 6, 477-481.

[42]Kitthawee S. and Edman J.D. (1995) Southeast Asian J. Trop. Med. Public. Health., 26, 582-585.

[43]Walton C., Handley J.M., Kuvangkadilok C., Collins F.H., Harbach R.E., Baimai V. and Butlin R.K. (1999) Med. Vet. Entomol., 13, 24-32.

[44]Sucharit S., Komalamisra N., Leemingsawat S., Apiwathanasorn C. and Thongrungkiat S. (1988) Southeast Asian J. Trop. Med. Public. Health., 19, 717-723.

[45]Sucharit S., Surathinth K., Chaisri U., Thongrungkiat S. and Samang Y. (1995) Mosq. Borne. Dis. Bull., 12, 1-6.

[46]Komalamisra N. (1989) Jpn. J. Sanit. Zool., 41, 69-80.

[47]Green C.A., Gass R.F., Munstermann L.E. and Baimai V. (1990) Med. Vet. Entomol., 4, 25-34.

[48]Baimai V., Kijchalao U. and Rattanarithikul R. (1996) J. Am. Mosq. Control. Assoc., 2, 97-105.

[49]Sharpe R.G., Hims M.M., Harbach R.E. and Butlin R.K. (1999) Med. Vet. Entomol., 13, 265-273.

[50]Choochote W., Rongsriyam Y., Leemingsawat S., Jitpakdi A., Komalamisra N., Surathin K., Somboon P., Chen B., Wongkamchai S., Jariyapan N., Tippawangkosol P., Pitasawat B. and Riyong D. (2002) Southeast Asian J. Trop. Med. Public. Health., 33 (Suppl 3), 23-28.

[51]Somboon P., Thongwat D., Choochote W., Walton C. and Takagi M. (2005) J. Am. Mosq. Control. Assoc., 21, 5-9.

[52]Sucharit S., Harrison B.A. and Rattanarithikul R. (1979) Mosq. Syst., 11, 163-171.

[53]Takai K., Kanda T., Ogawa K.I. and Sucharit S. (1987) J. Am. Mosq. Control. Assoc., 3, 148-153.

[54]Chabpunnarat S. (1988) M.S. Thesis, Mahidol University, Bangkok.

[55]Green C.A., Rattanarithikul R. and Charoensub A. (1992) Med. Vet. Entomol., 6, 335-341.

[56]Baimai V., Kijchalao U., Rattanarithikul R. and Green C.A. (1993) Mosq. Syst., 5, 116-123.

[57]Rongnoparut P., Yaicharoen S., Sirichotpakorn N., Rattanarithikul R., Lanzaro G.C. and Linthicum K.J. (1996) Am. J. Trop. Med. Hyg., 55, 589-594.

[58]Rongnoparut P., Sirichotpakorn N., Rattanarithikul R., Yaicharoen S. and Linthicum K.J. (1999) Am. J. Trop. Med. Hyg., 60, 508-515.

[59] Junkum A., Komalamisra N., Jitpakdi A., Jariyapan N., Min G.S., Park M.H., Cho K.H., Somboon P., Bates P.A. and Choochote W. (2005) J. Vector. Ecol., 30, 213-224.

[60]Green C.A., Rattanarithikul R., Pongprasit S., Sawadwongporn P. and Baimai V. (1991) Trans. R. Soc. Trop. Med. Hyg., 85, 35-36.
[61]Baimai V., Kijchalao U. and Rattanarithikul R. (1996) J. Am. Mosq. Control. Assoc., 12, 669-675.

[62]Sukowati S. and Baimai V. (1996) Genome., 39, 165-173.

[63]Sukowati S., Baimai V., Harun S., Dasuki Y., Andris H. and Efriwati M. (1999) Met. Vet. Entomol., 13, 408-414.

[64]Green C.A., Baimai V., Harrison B.A. and Andre R.G. (1985) Biol. J. Linn. Soc., 4, 321-328.

[65]Park M.H., Choochote W., Kim S.J., Somboon P., Saeung A., Tuetan B., Tsuda Y., Takagi M., Joshi D., Ma Y. and Min G.S. (2008) J. Am. Mosq. Control. Assoc., 24, 489-495.

[66]Choochote W. (2011) J. Insect. Sci., 11, 10.

[67]Choochote W., Jitpakdi A., Sukontason K., Chaithong U., Wongkamchai S., Pitasawat B., Jariyapan N., Suntaravitun T., Rattanachanpichai E., Sukontason K., Leemingsawat S. and Rongsriyam Y. (2002) Southeast Asian J. Trop. Med. Public. Health., 33 (Suppl 3), 29-35.

[68]Saeung A., Baimai V., Otsuka Y., Rattanarithikul R., Somboon P., Junkum A., Tuetun B., Takaoka H. and Choochote W. (2008) Parasitol. Res., 102, 499-507.

[69]Saeung A., Otsuka Y., Baimai V., Somboon P., Pitasawat B., Tuetun B., Junkum A., Takaoka H. and Choochote W. (2007) Parasitol. Res., 101, 1337-1344.

[70]Suwannamit S., Baimai V., Otsuka Y., Saeung A., Thongsahuan S., Tuetun B., Apiwathnasorn C., Jariyapan N., Somboon P., Takaoka H. and Choochote W. (2009) Parasitol Res., 104, 905-918.

[71]Thongsahuan S., Baimai V., Otsuka Y., Saeung A., Tuetun B., Jariyapan N., Suwannamit S., Somboon P., Jitpakdi A., Takaoka H. and Choochote W. (2009) Mem. Inst. Oswaldo. Cruz., 104, 558-566.

[72]Baimai V. (1988) Southeast Asian J. Trop. Med. Public. Health., 19, 667-680.

[73]Baimai V., Andre R.G., Harrison B.A., Kijchalao U. and Panthusiri L. (1987) Proc. Entomol. Soc. Wash., 89, 157-166.

[74]Paterson H.E. (1980) Evolution., 34, 330-331.

[75]Coluzzi M. (1970) Misc. publ. Entomol. Soc. Am., 7, 63-77.

[76]Saeung A. (2010) Ph.D. Thesis, Chiang Mai University, Chiang Mai.

[77]Peyton E.L. (1990) Mosq. Syst., 21, 197-205.

[78]Peyton E.L. and Harrison B.A. (1980) Mosq. Syst., 12, 335347.

[79]Baimai V., Harrison B.A. and Somchit L. (1981) Genetica., 57, 81-86.

[80]Sucharit S. and Choochote W. (1983) Mosq. syst., 15, 90-96.

[81]Hii J.L.K. (1985) Bull. Entomol. Res., 75, 185-197.

[82]Wibowo S., Baimai V. and Andre R.G. (1984) Can. J. Genet. Cytol., 26, 425-429.

[83]Rattanarithikul R., Harrison B.A., Harbach R.E., Panthusiri P. and Coleman R.E. (2006) Southeast Asian J. Trop. Med. Public. Health., 37 (Suppl 2), 1-128.

[84]Baimai V., Kijchalao U., Sawadwongporn P. and Green C.A. (1988) Southeast Asian J. Trop. Med. Public. Health., 19, 151161.

[85] Somboon P., Walton C., Sharpe R.G., Higa Y., Tuno N., Tsuda Y. and Takagi M. (2001) J. Am. Mosq. Control. Assoc.,17, 98-113.

[86]Somboon P., Thongwat D., Choochote W., Walton C. and Takagi M. (2005) J. Am. Mosq. Control. Assoc., 21, 5-9. 
[87]Somboon P., Rory A., Tsuda Y., Takagi M. and Harbach R.E. (2010) Zootaxa., 2651, 43-51.

[88]Harrison B.A., Rattanarithikul R., Peyton E.L. and Mongkolpanya K. (1990) Mosq. Syst., 22, 196-227.

[89]Van Bortel W., Trung H.D., Manh N.D., Roelants P., Verlé P. and Coosemans M. (1999) Trop. Med. Int. Hlth., 4, 257-265.

[90]Chen B., Harbach R.E. and Butlin R.K. (2002) Med. Vet. Entomol., 16, 253-265.

[91]Harbach R.E., Parkin E., Chen B. and Butlin R.K. (2006) Proc. Entomol. Soc. Wash., 108, 198-209.

[92]Rwegoshora R.T., Sharpe R.G., Baisley K.J. and Kittayapong P. (2002) Southeast Asian J. Trop. Med. Public. Health., 33, 694-701.

[93]Chareonviriyaphap T., Prabaripai A., Bangs M.J. and AumAung B. (2003) J. Med. Entomol., 40, 876-881.

[94]Sungvornyothin S., Muenvorn V., Garros C., Manguin S., Prabaripai A., Bangs M.J. and Chareonviriyaphap T. (2006) J. Vector. Ecol., 31, 252-261.

[95]Green C.A. (1982) Recent Developments in the Genetics of Insect Disease Vectors, Stipes Publishing Company, Champaign, Illinois.

[96]Green C.A. and Baimai V. (1984) Proceedings XV International Congress of Genetics, Oxford and IBH Publ. Comp. New Delhi., 3, 389-397.

[97]Green C.A., Baimai V., Harrison B.A. and Andre R.G. (1985) Biol. J. Linn. Soc., 4, 321-328.

[98]Rattanarithikul R. and Green C.A. (1986) Mosq. Syst., 18, 246 -278 .

[99]Rattanarithikul R. and Harbach R.E. (1990) Mosq. Syst., 22, 160-183.

[100]Walton C., Somboon P., O'Loughlin S.M., Zhang S., Harbach R.E., Linton Y.M., Chen B., Nolan K., Duong S., Fong M.Y., Vythilingum I., Mohammed Z.D., Trung H.D. and Butlin R.K. (2007) Infect. Genet. Evol., 7, 93-102.

[101]Thongwat D., Morgan K., O'Loughlin S.M., Walton C., Choochote W. and Somboon P. (2008) J. Am. Mosq. Control. Assoc. 24, 194-202.

[102]Morgan K., O'Loughlin S.M., Mun-Yik F., Linton Y.M., Somboon P., Min S., Htun P.T., Nambanya S., Weerasinghe I., Sochantha T., Prakash A. and Walton C. (2009) Mol. Phylogenet. Evol., 52, 588-601.

[103]Somboon P., Thongwat D., Morgan K. and Walton C. (2008) Parasitol. Res., 103, 1317-1322.

[104]Somboon P., Thongwat D. and Harbach R.E. (2011) Zootaxa., 2810, 47-55.

[105]Harbach R.E. (2004) Bull. Entomol. Res., 94, 537-553.

[106]Upatham E.S., Prasittisuk C., Ratanatham S., Green C.A., Rojanasunan W., Setakana P., Theerasilp N., Tremongkol A., Viyanant V., Pantuwatana S. and Andre R.G. (1988) Southeast Asian J. Trop. Med. Public. Health., 19, 259-269.

[107]Nanda N., Das M.K., Wattal S., Adak T. and Subbarao S.K. (2004) Ann. Entomol. Soc. Am., 97, 171-176.

[108]Alam M.T., Das M.K., Ansari M.A. and Sharma Y.D. (2006) Acta. Trop., 97, 10-18.

[109]Dusfour I., Michaux J.R., Harbach R.E. and Manguin S. (2007) Infect. Genet. Evol., 7, 484-493.

[110]Dusfour I., Blondeau J., Harbach R.E., Vythilingham I., Baimai V., Trung H.D., Sochanta T., Bangs M.J. and Manguin
S. (2007) J. Med. Entomol., 44, 723-731.

[111]Reid J.A. (1968) Stud. Inst. Med. Res. Malaya., 31, 1-520.

[112]Rao T.R. (1984) The Anophelines of India, Malaria Resarch Centre, Indian Council of Medical Research, New Delhi, India

[113]Sumruayphol S., Apiwathnasorn C., Komalamisra N., Ruangsittichai J., Samung Y. and Chavalitshewinkoon-Petmitr P. (2010) Southeast Asian J. Trop. Med. Public. Health., 41, 541547.

[114]Tan C.H., Vythilingam I., Matusop A., Chan S.T. and Singh B. (2008) Malar. J., 7, 52. 